\title{
Educational Management and Quality in an Intercultural University
}

\author{
Álvarez Sánchez Iván Noel \\ Universidad Autónoma Intercultural de Sinaloa, Mochicahui, El fuerte, Sinaloa, México \\ Cervantes Rosas María de los Ángeles \\ Universidad de Occidente, Guasave, Sinaloa, México \\ Sánchez Sulu Nancy \\ Universidad Autónoma del Carmen
}

\begin{abstract}
The implementation of administrative strategies to improve the quality of intercultural institutions is reflected in benefit of the main actor of higher education institutions which is the student. It is for this reason that the objective of this research is to analyze the strategies designed and implemented and the impact on the quality observed by the stakeholders. The analysis was carried out from the qualitative approach, collecting information through observation, review of documents, and interviews. As main findings, it can be mentioned that the educational management has a priority role as a substantive activity in the intercultural university which guarantees the quality of the services.
\end{abstract}

Keywords: administrative strategies, institutions of higher education, stakeholders

\section{Introduction}

Higher education is a key element for the economic development of a country, through which, knowledge, skills, and abilities for the performance of a profession are accredited and is the best guarantee of stable employment. In this sense in Mexico, intercultural universities are an emerging field of both academic research as well as political and institutional planning (Álvarez, Ceceña, \& Bojórquez, 2013).

In the application of administrative strategies, characteristics that are implemented to improve the educational management of the institution arise and this benefits the whole university community, but mainly in the formation of the student, with high standards of educational quality that are able to meet the needs and the challenges of the labor market; the student is the main element of the interest groups of higher education institutions and their demands must be met (Cervantes \& Aldeanueva, 2016).

This research is carried out in the Universidad Autonoma Indigena de Mexico (UAIM), located in the northern part of the State of Sinaloa, in the community of Mochicahui, corresponding to the municipality of El

\footnotetext{
Álvarez Sánchez Iván Noel, research professor, Ph.D., Department of Computer Systems, Universidad Autónoma Intercultural de Sinaloa.

Cervantes Rosas María de los Ángeles, research professor, Ph.D., Department of Administrative Economics Science, Universidad de Occidente Unidad Guasave.

Sánchez Sulu Nancy, research professor, Ph.D., Faculty of Administrative Economics of the Universidad Autónoma del Carmen.
} 
Fuerte, Sinaloa and provides relevant information on the application of administrative strategies with focus on quality and the improvement of services in intercultural higher education institutions.

\section{Research Problems}

The interest in studying this problem has as objective the growing need for knowledge related to educational management specifically in the application of administrative strategies that bring about substantial changes in intercultural institutions, in order to improve the quality of education, the services are to be considered by society as an attractive option for the development of knowledge, skills, attitudes, and values needed in professional life.

For this reason, the qualitative method was used to analyze the relationship between administrative strategies in educational management for service quality at the Universidad Autónoma Indígena de México (UAIM) as an object of study, located in Mochicahui, El Fuerte, Sinaloa, Mexico.

\section{Literature Review}

The proposal of the intercultural approach focuses on contact and reciprocal influence and it also promotes positively the interaction between cultures, having its premises that these are not static but dynamic and are enriched and dynamized as a result of their exchange, by which agrees with Diez and Zuany (2008), intercultural education has been fundamentally oriented towards the attention of indigenous peoples, with a limited vision of diversity and the concept of cultural.

In this context, in the UAIM, interculturalism helps to attend and improve the axis of language, culture and, the link with the community, through deep recognition of the diversity of the human species in terms of cultures or world views, to which not only corresponds to dances and costumes, but also different value systems, diverse accumulations of knowledge, different modes of knowledge production, and different modalities of learning.

There are many theoretical models and empirical studies on the structure and functioning of the educational system and social organizations in general, including the psycho-sociological model of Getzels and Guba (1957), and they reduce organizational behavior the interrelationship of three-dimensional: institutional dimension, individual dimension, and group dimension.

In this sense, the administration fulfills a mediating role between the three dimensions, determining significantly the nature of the organizational behavior according to the type of administrative mediation that has been adopted, therefore, it is possible to conceive three different perspectives of administration or educational management with their respective types of mediation and their corresponding predominant criteria of administrative performance (Sander, 1994).

The following is an analysis of the nature of the three functionalist management perspectives with their respective types of mediation, the objectives they pursue, and the prevailing administrative criteria.

\section{Bureaucratic Administration}

The bureaucratic administration is a conceptual derivation of the sociological theories of the classic school of administration exposed by Taylor (1987), Fayol, and Weber, at the beginning of century XX, in times of the consolidation of the industrial revolution. Applied to educational management, the bureaucratic perspective takes the form of an administrative style that emphasizes the institutional dimension of the education system and is oriented, primarily, by the expectations, rules, and bureaucratic regulations; according to this orientation, 
the educational organization is conceived structurally as a closed system of functions or roles to which corresponds rights and institutional duties (Sander, 1994).

In this sense (Baldridge, 1977; Petrella, 2007), it has applied Weber's typical-ideal construction to universities in their bureaucratic aspect; he stressed, therefore, that the university is a complex organization, with dependence on the state and with bureaucratic relations of authority, formal hierarchy, formal channels of communication, and formal political rules Bureaucratic aspects are found throughout the university, can be noticed even more in the areas of processing school control, archiving, registration, accreditation and qualification requirements, routine activities, among others; designed to address the mass management of students.

In his professional work, the bureaucratic administrator is attentive to the compliance with the laws and norms that govern the functioning of the educational organization and the defense of its interests as a system, without taking into account the importance of its participants as individuals. Their concern is to create an organizational climate that favors the effectiveness of the educational system for the achievements of its objectives, relegating the individual efficiency of participants to a plane of secondary importance (Sander, 1994).

\section{Idiosyncratic Administration}

It is a conceptual derivation of the psychological theories of administration associated with the movement of human relationships that Mayo, Roethlisberger, and Dickson, their application in educational management, takes the form of an administrative style that emphasizes the individual dimension of the educational system and is oriented, primarily, to the needs and personal dispositions of its participants (Sander, 1994).

With this orientation, the educational organization is conceived as a partially open system based on the interpretation of the actions and interactions of the people participating in it, facilitating the development of an organizational climate appropriate for subjective growth, where each person is considered as a unique individual with a distinct personality, defined by an own set of needs and dispositions that are reflected in their behavior, while paying little attention to institutional effectiveness in achieving institutional objectives.

\section{Integrative Management}

Integrative management is a conceptual derivation of the psychosociological management theories formulated by Barnard and Simon (1959) and later developed by Argyris (1964), McGregor (1960), Halpin (1966), Griffiths and Getzels (1968), their application in educational management, the integrative perspective is simultaneously or alternately concerned with the sociological and psychological aspects of the educational system and its schools and universities (Sander, 1994).

That is, it deals with the interaction between the institution and the individual, between role and personality, and between bureaucratic expectations and needs and personal dispositions, according to this perspective of interdisciplinary nature, the educational institution is conceived as an open system; the above implies the scaling down of the sociological reductionism of the bureaucratic administration and the psychological reductionism of the idiosyncratic administration.

\section{Formulation and Implementation of Strategies}

The main activities of the formulation of the Mintzberg's (1977) strategy include the identification of opportunities and threats in the environment in which the organization is developed, as well as the attributing estimation of risk to each of the discernible options, so therefore being inclined by a particular election, the strengths and weaknesses of the institution must be valued, in addition to the available resources and the 
amplitude of it. Likewise, it will be necessary to determine, as objectively as possible, their actual and potential capacity to take advantage of perceived needs both internally and externally as well as their ability to cope with the risks inherent in their performance.

\section{Schools of Strategic Thinking}

The strategy considers multiple definitions and its utility has generated debates among diverse authors throughout the years; in this context, Mintzberg, Lampel, and Ahlstrand (1998), in their book Strategy Safari, were given the task of bringing together the main schools of strategy designed to apply the best of them; each school of strategic thinking provides a particular focus on the strategy and its formulation process; for this research the following strategies were selected:

(1) Strategy of the school of design. The main virtue of this school is the systematic use of analysis of the external environment, responsible for the development of the SWOT (strength, weakness, opportunity, and threat) model; the information in this type of studies is used to identify the opportunities that exist and thus to advance the company to the situations of the market and its purpose is to adapt the opportunities and threats existing in the environment with the strengths and weaknesses of the organization. Responsible for the execution of this kind of analysis is the top manager.

(2) The school of power strategy. This school recognizes that power exists within the organization and its premise is to form strategies based on influence, emphasizing the use of power and politics to negotiate strategies favorable to particular interests; for this school, strategies are emerging and take the form of positions or tactics and power relations are given at the micro and macro levels. In this sense, the existence of different interests supposes the strategy as a political process; at the macro level, power relations reflect the interdependence of an organization with its environment.

(3) The strategy of the school of learning. It is devised as a process in which patterns of behavior may arise from which solutions are offered to situations that manifest; the role of the leader is not precisely to preconceive a strategy but to manage the process of strategic learning, which takes place during the confrontation of thought and action stimulating the guide's retrospective thinking about his own behaviors.

It is necessary to experience things, observe the consequences, understand them, and continue to advance; this mechanism is necessarily given the complex and unforeseen nature of the context of the organizations within which the actions of the government and external groups are located, this school breaks with the judgment of conceiving the strategy as a linear process in which the thought ends and then the action begins, in other words, it does not follow the process of first formulating and then carrying out.

(4) The strategy of the school of planning. The strategy arises from a formal process of conscious and controlled planning that establishes deadlines, programs, and budgets, which respond optimally to the goals of the organization; the strategic planning starts from the assumption of stability in the company in such a way that it is carried out around already existing categories in the same organization which can result in the incompatibility with unexpected changes or with the latent uncertainty in the companies.

(5) The strategy of the cultural school. Developing a competitive perspective based on the creation of a culture strongly associated with a strategy; Cultures that "live" all members of the company ensure the development of the strategy, for example, culture of quality of service or customer orientation, in another organization may be the culture of accelerated innovation, in another company is the culture of responsiveness; any of these strategies will be successful if it is deeply rooted in each subject. 


\section{The Quality of Educational Service}

The quality of education now occupies a priority place in the processes of university transformation. Tunnermann (2009) stated that the pertinence, effective and transparent management, and quality in services offered fidelity to the substantial missions of the University, International dimension of university work and the exercise of responsible autonomy.

According to UNESCO (1998), quality refers to:

To the main functions and activities of higher education: quality of education, training and research, it translates into quality of staff and programs, as a consequence of teaching and research, attention must also be paid to quality of the students, of the infrastructure and the environment of the institution. (UNESCO, 1998, p. 33)

UNESCO recognized that in order to achieve quality in higher education, the process of evaluation and appreciation of quality must count on the active participation of administrative, teaching and research staff, students, and leaders and should focus on a process of modernization and accountability.

In Mexico, based on State-sponsored educational policies and initiatives of the National Association of Universities and Institutions of Higher Education (ANUIES), different programs and mechanisms have been designed and implemented to recover the discourse of quality and focused on the evaluation with the purpose of configuring a quality higher education system.

In this sense, the quality of education refers to the characteristics of the process and the results in the formation of man, conditioned historically and socially, which take concrete expression from the prevailing philosophical, pedagogical, psychological and sociological paradigms in the society in question (Paredes \& García, 2013).

Recalling the purpose of quality management systems to meet customer's needs, Sangüesa (2006) and Mejías, Teixeira, Rodríguez, and Arzola (2010) argued that services must pay special attention to prevention of errors; since in this case, problems arise as the service is being executed and a solution must be given as quickly as possible.

In intercultural higher education institutions, it is important to delimit what is meant by clients referring to this research to students and employees, since the last one, does not provide a service, but is part of it.

\section{Objective}

The present research focuses on topics that are widely studied, such as administrative strategies, educational management, and quality in services with the purpose of improving activities within educational institutions. In addition, it is intended to make a contribution to knowledge of a theoretical and explanatory nature, since it is exposed because a phenomenon occurs and under what conditions it is given, as well as a methodological contribution by the application of data collection tools and techniques. Therefore, the objective of this research is to analyze the impact of administrative strategies for the achievement of service quality in an Intercultural Higher Education Institution.

\section{Methods}

One of the central aspects in any research project is the methodological design; to support a clear definition of the object of study is not something simple, since its relevance, as a starting point, supports a union of elements of analysis structured under a congruence with the results to be achieved. 
In this research, the qualitative approach was used since it explores a social problem from the point of view of the informants (Rojo, 2003) and it was decided to use the case study method proposed by Taylor and Bogdan (1987), as a strategy to achieve the research objective and as an instrument of information collection, the interview was used which allowed to deepen on the explanatory analysis on what is the impact off administrative strategies for the achievement of quality in the Universidad Autonóma de México.

\section{Results}

After applying the interviews, we proceeded to group the information obtained according to categories finding that in the design and implementation of administrative strategies in the UAIM, wich that is are includedas indispensable activities to carry out the educational functions from a vision of the business administration, and have as main objective, to improve and streamline the services, academic and administrative processes that lead to raise the quality of education.

The UAIM carried out planning strategies (Mintzberg, 1997), which are used as a guide for the performance of activities, which are supported by the strategies developed in each area of the university, there is a design of academic strategies, linkage, organization, and postgraduate. The activities mentioned as guidelines in the UAIM, are similar to Quinn's (1993) concept of strategy, integrate the main goals and policies of an organization, and aim to raise quality education management.

With the information obtained from the documentary analysis, the UAIM carried out a planning strategy that is used as a guide for the performance of the activities, which are supported by the strategies developed in each area of the university, which means there is a design of academic strategies, educational, liaison, organization, and postgraduate programs.

The above, it is noticed that the activities indicated as guides in the UAIM coincide with the strategies of Quinn (1993) that defines them as the pattern or plan that integrates the main goals and policies of an organization. In this sense, contrasting the opinions of the directors of the UAIM, they recognized the importance and use of the strategy as a necessary tool to make decisions when required.

\section{Conclusion}

This research is carried out assuming the importance of intercultural higher education in Mexico and the role it plays in teaching, research, and services links with the State, society, and productive sectors; the university relies on administrative strategies for the performance of its functions, but it is necessary to raise efficiency aimed at achieving: academic quality, financial resources, administrative processes, and physical and technological infrastructure; to enable UAIM to provide relevant and quality education for young people of indigenous origin and poor sectors.

In this sense, the activities developed in the educational management for the quality of services must be previously analyzed, in order to be as rational as possible at the time of making the corresponding decisions, which is why it is considered indispensable the design of administrative strategies that structures and orders the activities and tasks to be developed in order to guarantee the success of the operations.

The current problems in the management of education, to raise the quality of services in the IESI, are mainly of subjective nature, motivated by a dynamic of development that goes beyond the possibilities of coordination and execution effective on the part of the executives involved in these processes. 
This causes the expected results to be out of time and partially obtained, giving an idea of inefficiency. Also conventional or traditional approaches have prevailed so that the old problems are not able to be solved, for example, the constraints of material and financial resources that are fundamental to the structuring and consolidation of projects have also prevailed.

Therefore, the quality of service is of vital importance for the success of any organization, since a high level of the same provides for the companies considerable benefits in terms of productivity, reduction of costs, motivation of the personnel, differentiation with respect to the competition, loyalty, and training of new clients.

\section{References}

Álvarez, S. I., Ceceña, M. G. I., \& Bojórquez, E. M. (2013). La Gestión educativa como factor de calidad en una universidad intercultural (Educational management as a quality factor in an intercultural university). Revista Ra Ximhai, 4.

Argyris, C. (1964). Integrating the individual and the organization. Nueva York: Wiley.

Baldridge, V., Curtis, D., Ecker, G., Riley, G. (1977). Alternative models of governance in higher education. Governing academic organizations (pp. 2-25). USA, Berkeley: McCutchan Publishing Corporation.

Cervantes, M., \& Aldeanueva, I. (2016). Las instituciones de educación superior y el desarrollo sustentable: Estudio exploratorio desde la perspectiva del alumno (Institutions of higher education and sustainable development: An exploratory study from the perspective of the student). Revista Ra Ximhai, 12(6), 259-267.

Chester, I. B. (1938). The functions of the executive. Cambridge, Mass: Harvard University Press.

Dietz, G., \& Zuany, R. (2008). Interculturalizando la educación superior (Interculturalising higher education evaluation of the quality of university services). Revista Trace.

Getzels, J. W., \& Guba, E. G. (1957). Social behavior and the administrative process. School Review, 65(4), 423-441.

Mejías, A., Teixeira, J., Rodríguez, J., \& Arzola, M. (2010). Evaluación de la Calidad de los Servicios Universitarios (Evaluation of the quality of university services). Eighth LACCEI Latin American and Caribbean Conference for Engineering and Technology, 201, 1-10.

Mintzberg, H. (1997). El proceso estrategico (The strategic process). Mexico: Editorial Prentice All.

Mintzberg, H., Ahlstrand, B. W., \& Lampel, J. (1998). Strategy safari: A guided tour through the wilds of strategic management. New York: Free Press.

Murrillo, J., \& Krichesky, G. (2012). El proceso de cambio escolar: Una guía para impulsar y sostener la mejora de las escuelas (The shoool change process: A guide to boosting and sustaining school improvement). Revista Iberoamericana Sobre la Calidad, Eficacia y Cambio en Educación, 10(1), 1-12.

Paredes, C. V., \& García, C. F. (2013). Universidad autónoma de estado de hidalgo (Autonomous university of hidalgo state). Retrieved May 23, 2014 from dedgsa.uaeh.edu.mx: dgsa.uaeh.edu.mx/revista/icea/IMG/pdf/2_-_No.7.pdf

Petrella, C. (2007). Teorias de sistemas (System theories) (pp. 45-60). Retrieved January 10, 2014 from www.fing.edu.uy:ww.fing.edu.uy/catedras/.../Teoriadesistemasaplicadoaorganizacis

Quinn, J., \& Mintzberg, H. (1993). Estrategias para el cambio (Strategies for change). In H. Mintzberg and J. B. Quinn (Eds.), El proceso estratégico. Conceptos, contextos y casos (The strategic process. Concept, contexts ans cases). México: Prentice-Hall.

Rojo, P. N. (2003). La investigación cualitativa (Qualitative research). Health Applications Magazine, 24(2). 58-76.

Sander, B. ( 1994). Gestión educativa y calidad de vida (Educational management and quality of life). Revista Educación, II(118), 34-49.

Taylor, S., \& Bogdan, R. (1987). Introducción a los métodos cualitativos de la investigación (Introduction to quaitative methods of research). Barcelona, España: Editorial Paidios.

Tunnermann, C. (2009). Pertinencia y calidade en educación superior (Pertinence and quality in higher education). Retrieved from www.unesdoc.unesco.org/images/0016/001620/16207

UNESCO. (2008). Conferencia mundial sobre educación superior (World conference on higher education). Paris: Editorial UNESCO. 